ISSN: 1410-8917

Jurnal Kimia

Sains \&

Aplikasi
Jurnal Kimia Sains dan Aplikasi Journal of Scientific and Applied Chemistry

Journal homepage: http://ejournal.undip.ac.id/index.php/ksa

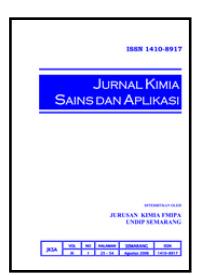

\title{
Isolasi, Identifikasi dan Uji Sitotoksik Senyawa Steroid dari Daun Binahong (Anredera Cordifilia (Ten.) Stennis)
}

\author{
Yuliana Manik $^{\mathrm{a}}$, Enny Fachriyah ${ }^{\mathrm{a}^{*}}$, Dewi Kusrini ${ }^{\mathrm{a}}$ \\ a Organic Chemistry Laboratory, Chemistry Department, Faculty of Sciences and Mathematics, Diponegoro University, Jalan Prof. \\ Soedarto, Tembalang, Semarang \\ * Corresponding author: enny.fachriyah@live.undip.ac.id
}

\begin{tabular}{|c|c|}
\hline & Abstract \\
\hline Article Info & The Binahong (Anredera cordifolia (Tenore) Steenis) is a medicinal plant that potential to \\
\hline Keywords: & cure a wide variety of diseases and useful as antibacterial, antioxidant and antiseptic. \\
\hline Binahong, steroid, & Steroid was known to be useful as an antibacterial. In this study, isolation, identification \\
\hline n-hexane extract, & and a test of cytotoxic to $n$-hexane extract of binahong leaves have been conducted. \\
\hline cytotoxic & Analysis of white crystal isolate with a melting point of $154,9-155,3^{\circ} \mathrm{C}$ was done using \\
\hline & FTIR spectrophotometer and LC-MS. Analysis of isolate using FT-IR spectrophotometer \\
\hline & indicated that the isolate contained groups of $-\mathrm{OH},-\mathrm{C}-\mathrm{O}, \mathrm{C}=\mathrm{C},-\mathrm{CH}_{3}$ and $-\mathrm{CH}_{2}$. The LC- \\
\hline & $\begin{array}{l}\text { MC chromatogram indicated that the compounds had a molecular weight of } 351 \mathrm{~g} / \mathrm{mol} \text {, } \\
\text { which indicated the stigmasterol (steroid alcohol). The results of cytotoxic test with }\end{array}$ \\
\hline & $\begin{array}{l}\text { BSLT method showed that only fraction A was toxic with value of } L_{50} 9.931 \mathrm{ppm} \text {, extract } \\
\text { of } n \text {-hexane, fraction } B \text {, fraction } C \text {, and fraction } D \text { were not toxic with value of } L C_{50} \text { were }\end{array}$ \\
\hline & $\begin{array}{l}\text { of } \mathrm{n} \text {-hexane, fraction } \mathrm{B} \text {, fraction } \mathrm{C} \text {, and fraction } \mathrm{D} \text { were not toxic with value of } \mathrm{LC}_{50} \text { were } \\
463.877 \mathrm{ppm}, 1664.039 \mathrm{ppm}, 1341.507 \mathrm{ppm} \text { and } 172.213 \mathrm{ppm} \text {. }\end{array}$ \\
\hline
\end{tabular}

\begin{abstract}
Abstrak
Binahong (Anredera cordifolia (Tenore) Steenis) adalah tanaman obat potensial yang dapat mengatasi berbagai jenis penyakit dan berguna sebagai antibakteri, antioksidan dan antiseptik. Steroid diketahui bermanfaat sebagai antibakteri. Pada penelitian ini telah dilakukan isolasi, identifikasi dan uji sitotoksik terhadap ekstrak n-heksana. Analisis isolat yang berupa kristal putih dengan titik leleh sebesar 154,9-155,30C dilakukan menggunakan spektrofotometer FT-IR dan LC-MS. Hasil analisis FT-IR menunjukkan isolat memiliki gugus $-\mathrm{OH},-\mathrm{C}-\mathrm{O}, \mathrm{C}=\mathrm{C},-\mathrm{CH} 3$ dan $-\mathrm{CH} 2$. Sedangkan hasil LC-MS menunjukkan bahwa isolat memiliki berat molekul $351 \mathrm{~g} / \mathrm{mol}$. Berat molekul ini diduga dimiliki oleh senyawa stigmasterol (steroid alkohol) yang telah mengalami pemutusan ikatan pada rantai cabang. Hasil uji sitotoksik dengan metode BSLT menunjukkan bahwa hanya fraksi A bersifat toksik dengan harga $\mathrm{LC}_{50}$ sebesar 9,931 ppm sedangkan ekstrak n-heksana, fraksi B, C, dan D tidak bersifat toksik dengan harga $\mathrm{LC}_{50}$ berturut-turut 463,877 ppm, 1664,039 ppm, 1341,507 ppm dan 172,213 ppm.
\end{abstract}

Kata kunci:

Binahong, steroid, ektrak n-heksana, sitotoksik

\section{Pendahuluan}

Binahong (Anredera cordifolia (Tenore) Steenis) adalah tanaman obat potensial yang dapat mengatasi berbagai jenis penyakit dan berguna sebagai antibakteri, antioksidan dan antiseptik [1]. Kemampuan daun binahong untuk menyembuhkan berbagai jenis penyakit berkaitan erat dengan senyawa aktif yang terkandung di dalamnya, salah satunya adalah steroid. Kemampuan steroid dari daun binahong perlu diaplikasikan, terutama dalam pembuatan obat. Penelitian ini dilakukan untuk mengisolasi, mengidentifikasi dan menguji sitotoksik senyawa steroid ekstrak $n$-heksana daun binahong. 


\section{Metodologi}

\section{Alat \& Bahan}

Sampel yang digunakan dalam penelitian ini adalah daun binahong yang berasal dari kota Brebes, isolasi dan uji penapisan fitokimia menggunakan n-heksana, kloroform, etil asetat, benzena, diklorometana, aseton, silika gel, pereaksi Lieberman-Burchad (anhidrida asam asetat p.a, asam sulfat pekat p.a), pereaksi Meyer (merkuri (I) klorida p.a, kalium iodida p.a), larutan besi (III) klorida $1 \%$, asam klorida pekat, serbuk magnesium, amilalkohol p.a, amonia $25 \%$ teknis, kloroform p.a, asam klorida $37 \%$ p.a , akuades, tween ${ }^{\circledR} 20$ dan Artemia salina digunakan untuk uji sitotoksik steroid.

Peralatan yang digunakan dalam penelitian ini adalah gelas standar penelitian, satu set alat maserator, blender, kolom kromatografi, satu set alat rotary evaporator, neraca analitis, plat tetes, pipet tetes, pipet mikro, kaca pembesar, botol vial, cawan penguapan, akuarium penetasan, satu set alat KLT, lampu UV, spektrometer FT-IR dan LC-MS.

\section{Preparasi sampel}

Daun Binahong diiris tipis-tipis, kemudian keringanginkan (simplisia). Setelah kering, simplisia diblender hingga menjadi serbuk daun binahong kemudian dimaserasi dengan $\mathrm{n}$-heksana.

\section{Penapisan fitokimia}

Serbuk daun binahong dan ektrak n-heksana diuji dengan penapisan fitokimia untuk mengetahui kandungan golongan senyawa kimianya meliputi uji saponin, uji flavonoid, uji fenolik, uji alkaloid, uji triterpenoid dan ujisteroid/triterpenoid.

\section{Isolasi steroid}

Serbuk daun binahong dimaserasi menggunakan pelarut $\mathrm{n}$-heksana. Kemudian ekstrak yang didapatkan dievaporasi menggunakan evaporator. Ekstrak yang didapat kemudian dilakukan KLT dengan menggunakan campuran n-heksana, kloroform, etil asetat, benzena dan diklorometana dengan perbandingan tertentu. Setelah didapatkan komposisi eluen yang sesuai, kemudian dilakukan pemisahan senyawa-senyawa yang terdapat pada ekstrak n-heksana tersebut menggunakan kromatografi kolom. Eluen yang digunakan pada kromatografi kolom adalah eluen terbaik hasil kromtografi lapis tipis. Fraksi yang keluar ditampung dalam botol vial. Dari seluruh fraksi yang diperoleh dilakukan uji KLT menggunakan campuran nheksana, kloroform, etil asetat, benzena dan diklorometana. Fraksi yang menghasilkan noda sama digabungkan menjadi satu. Kemudian dilakukan uji steroid, fraksi yang mengandung steroid kemudian dilakukan KLT preparatif menggunakan campuran eluen $\mathrm{n}$-heksana, kloroform, etil asetat, benzena dan diklorometana dengan perbandingan tertentu. Setelah didapatkan noda-noda pada plat KLT, kemudian diuji steroid kembali. Setelah didapatkan bahwa ada senyawa steroid pada noda tersebut, kemudian dikerok dan dimurnikan.
Uji kemurnian dan pemurnian

Steroid hasil isolasi dilakukan uji kemurnian menggunakan KLT dengan berbagai macam campuran pelarut yaitu n-heksana, kloroform, etil asetat, benzena, diklorometana dan aseton serta menggunakan KLT dua dimensi. Apabila hanya didapatkan satu noda, maka dapat dikatakan bahwa steroid telah murni.

\section{Analisis steroid}

Analisis steroid menggunakan spektrometer FT-IR untuk mengetahui gugus fungsi steroid dan spektrometer LC-MS untuk mengetahui berat molekul steroid.

\section{Uji sitotoksik dengan metode Brine Shrimp Lethality} Test(BSLT)

Uji sitotoksik dilakukan dengan metode BSLT. Sampel yang diujikan meliputi ekstrak $\mathrm{n}$-heksana dan fraksi fraksi hasil kromatografi kolom ( FA, FB, FC dan FD).

Telur Artemia salina menetas dalam waktu 2 hari untuk menjadi larva. Larva dibiarkan hidup selama 2 hari dan siap digunakan. Masing-masing 10 larva Artemia salina dimasukkan ke dalam vial yang berisi sampel yang dilarutkan dalam air laut dengan konsentrasi 10 ppm,100 ppm, 1000 ppm, dan blanko (sampel) selama 24 jam. Pembuatan variasi konsentrasi dilakukan dengan penambahan Tween ${ }^{\circledR}$ 20. Uji toksisitas diukur berdasarkan jumlah larva A.salina yang mati. Pengulangan dilakukan sebanyak 3 kali. LC $_{50}$ diperoleh berdasarkan analisis probit [2].

\section{Hasil Dan Pembahasan}

Hasil maserasi serbuk daun binahong sebanyak 750 menggunakan pelarut $n$-heksana menghasilkan ekstrak n-heksana berbentuk pasta berwarna hijau kehitaman sebanyak 35,76 g. Serbuk daun binahong dan ekstrak n-heksana kemudian dilakukan uji penapisan fitokimia. Hasil penapisan fitokimia menunjukkan bahwa serbuk daun binahong mengandung senyawa golongan saponin, flavonoid, steroid dan triterpenoid, sedangkan ekstrak n-heksana daun binahong mengandung senyawa golongan flavonoid dan steroid.

Identifikasi kandungan steroid dilakukan dengan cara mereaksikan dengan pereaksi Liberman-Buchard ( 2 tetes anhidrida asam asetat dan 1 tetes asam sulfat pekat). Keberadaan steroid ditunjukkan dengan adanya warna ungu [3]. 


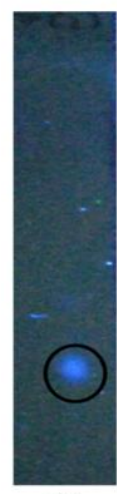

(A)

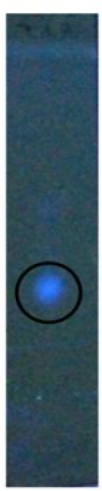

(B)

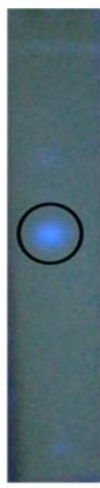

(C)
(A) pelarut benzena

(B) pelarut benzena : kloroform (1:1)

(C) pelarut benzena : diklorometana (1:1)

Gambar 1. Hasil uji kemurnian fraksi A dengan KLT berbagai pelarut di bawah lampu uv $365 \mathrm{~nm}$

Isolasi steroid dengan metode kromatografi kolom menggunakan pelarut benzena : kloroform : diklorometana (1:1:1) menghasilkan 4 fraksi besar (FA, FB, FC dan FD) dengan pola noda yang berbeda-beda. Terhadap fraksi besar A, B, C dan D dilakukan uji kualitatif terhadap steroid dengan penampak bercak Lieberman-Burchad. Pada tahap ini fraksi A memberikan uji positif terhadap steroid dengan ditandai terbentuknya warna ungu kehijauan setelah disemprot penampak bercak Lieberman-Burchad sehingga fraksi A dilanjutkan ke tahap berikutnya. Fraksi A dilakukan KLT preparatif dan diuji kemurnian dengan KLT berbagai pelarut dan KLT 2 dimensi. Hasil uji kemurnian fraksi A dengan KLT berbagai pelarut ditampilkan pada gambar 1.

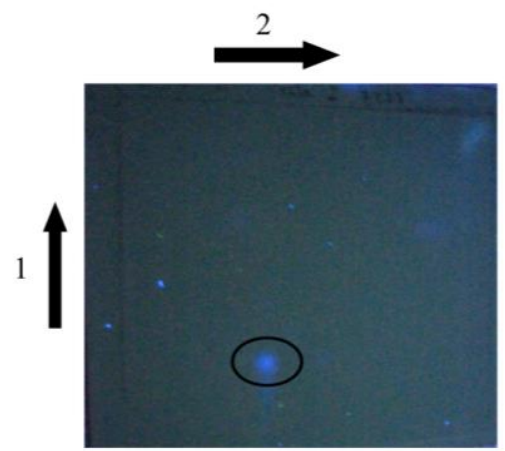

Keterangan:

(fasa gerak 1) benzena : kloroform : diklorometana 1:1:1

(fasa gerak 2) benzena : kloroform 1:1

Gambar 2. Hasil uji kemurnian fraksi A dengan KLT 2 dimensi

Uji kemurnian dilanjutkan dengan KLT 2 dimensi dengan pelarut benzena : kloroform : diklorometana (1:1:1) dan benzena : kloroform (1:1). Hasil uji kemurnian dengan KLT 2 dimensi ditampilkan pada gambar 2.

Berdasarkan hasil analisis menggunakan KLT berbagai pelarut maupun KLT 2 dimensi terhadap noda uji menunjukkan adanya noda tunggal (1 noda) sehingga dapat disimpulkan bahwa isolat (steroid) relatif murni.
Isolasi steroid dari ekstrak n-heksana menghasilkan isolat berupakristal berwarna putih dengan rendemen hasil sebesar $4 \%$ dari ekstrak nheksana dengan titik leleh $154,9-155,3^{\circ} \mathrm{C}$. Titik leleh ini mendekati titik leleh stigmasterol, jenis steroid alkohol yang memiliki titik leleh $154-155^{\circ} \mathrm{C}$ [4].

Analisis isolat steroid dilakukan menggunakan spektofotometer FT-IR dan LC-MS. Hasil analisis isolat steroid menggunakan FT-IR ditampilkan pada tabel 1.

Tabel 1: Hasil analisis dengan FT-IR isolat steroid [5]

\begin{tabular}{cc}
\hline $\begin{array}{c}\text { Bilangan Gelombang } \\
\left(\mathrm{cm}^{-1}\right)\end{array}$ & Jenis Vibrasi \\
\hline 3441,01 & Vibrasi ulur O-H bebas \\
2931,80 & Vibrasi ulur -C-H alifatik \\
asimetri \\
2862,36 & Vibrasi ulur $-\mathrm{C}-\mathrm{H}$ alifatik \\
simetri \\
1627,92 & Vibrasi ulur C=C \\
1573,91 & Vibrasi ulur C=C \\
1103,28 & Vibrasi ulur C-O alkohol \\
802,39 & Vibrasi tekuk C-H $\mathrm{H}_{2}$ \\
\hline
\end{tabular}

Analisis isolat dilanjutkan dengan menggunakan LC-MS. Data spektogram massa hasil analisis isolat steroid menggunakan LC-MS ditampilkan pada gambar 3.

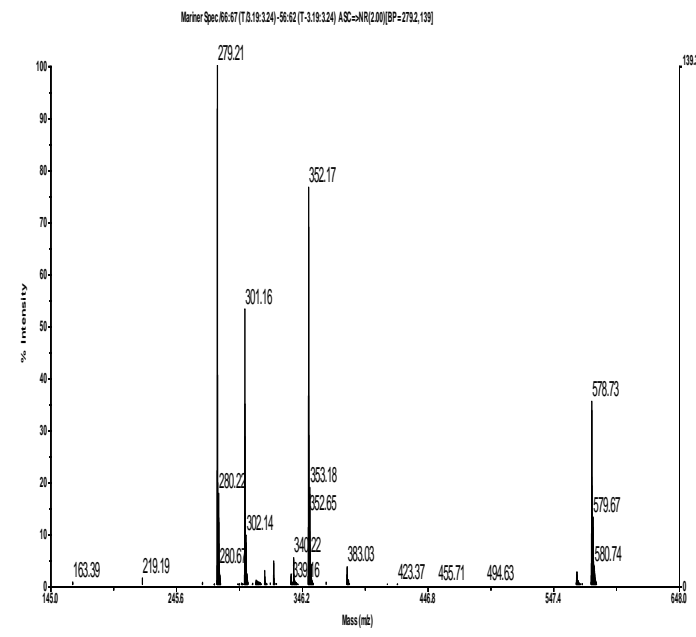

Gambar 3. Spektogram massa isolat steroid daun binahong

Berdasarkan hasil analis isolat menggunakan spektofotometer FT-IR diketahui bahwa isolat memiliki gugus $-\mathrm{OH}, \mathrm{C}-\mathrm{O}$ alkohol, $\mathrm{C}=\mathrm{C},-\mathrm{CH}_{3}$ dan $-\mathrm{CH}_{2}$. Jenis Gugus fungsi yang dimiliki isolat steroid ini mengindikasikan jenis gugus fungsi yang dimiliki oleh steroid yang mengandung gugus - $\mathrm{OH}$. Sedangkan hasil analisis isolat menggunakan LC-MS menunjukkan bahwa isolat memiliki berat molekul $351 \mathrm{~g} / \mathrm{mol}$ yang ditandai dengan munculnya $[\mathrm{M}+\mathrm{H}]^{+} 352,17 \mathrm{~g} / \mathrm{mol}$. Berat molekul ini diduga dimiliki oleh senyawa stigmasterol yang telah mengalami pemutusan ikatan pada rantai cabang [4]. Struktur molekul senyawa stigmasterol ditampilkan pada gambar 4 . 
<smiles>CCC(/C=C/C(C)C1CCC2C3CC=C4CC(O)CCC4(C)C3CCC12C)C(C)C</smiles>

Gambar 4. Struktur molekul senyawa stigmasterol

Senyawa stigmasterol merupakan jenis steroid alkohol yang biasa ditemukan pada tumbuhan famili Basellaceae. Stigmasterol memiliki berat molekul 412 $\mathrm{g} / \mathrm{mol}$ dan dapat mengalami pemutusan ikatan pada berat molekul $351 \mathrm{~g} / \mathrm{mol}$ [6].

UJi sitotoksik dengan metode Brine Shrimp Lethality Test (BSLT) terhadap ekstrak n-heksana, fraksi A, fraksi $\mathrm{B}$, fraksi C dan fraksi D menunjukkan bahwa menunjukkan bahwa hanya fraksi A yang bersifat toksik dengan harga $\mathrm{LC}_{50} 9,931 \mathrm{ppm}\left(\mathrm{LC}_{50}<10 \mathrm{ppm}\right)$ sedangkan ekstak n-heksana, fraksi B, fraksi C dan fraksi D tidak bersifat toksik dengan harga $\mathrm{LC}_{50}$ berturut-turut 463,877 ppm; 1664,039 ppm; 1341,507 ppm dan 172,213 ppm $\left(\mathrm{LC}_{50}>100 \mathrm{ppm}\right)[7]$.

\section{Kesimpulan}

Jenis steroid dalam daun binahong Anredera cordifolia (Tenore) Steenis) adalah stigmasterol (steroid alkohol) sedangkan hasil uji sitotoksik dengan metode Brine Shrimp Lethality Test (BSLT) terhadap ekstrak nheksana dan fraksi-fraksi hasil kromatografi kolom (FA, FB, FC dan FD) menunjukkan bahwa hanya fraksi A yang bersifat toksik dengan harga $\mathrm{LC}_{50} 9,931 \mathrm{ppm}\left(\mathrm{LC}_{50}<10\right.$ ppm) sedangkan ekstak n-heksana, fraksi B, fraksi C dan fraksi $\mathrm{D}$ tidak bersifat toksik dengan harga $\mathrm{LC}_{50}$ berturut-turut 463,877 ppm; 1664,039 ppm; 1341,507 ppm dan 172,213 ppm ( LC $\left._{50}>100 \mathrm{ppm}\right)$.

\section{Daftar Pustaka}

[1] Yellia Mangan, Solusi Sehat Mencegah \& Mengatasi Kanker, AgroMedia, 2009.

[2] B. N. Meyer, N. R. Ferrigni, J. E. Putnam, L. B. Jacobsen, D. E. Nichols, J. L. McLaughlin, Brine Shrimp: A Convenient General Bioassay for Active Plant Constituents, Planta Med, 45, 05, (1982) 31-34 http://dx.doi.org/10.1055/s-2007-971236

[3] RW Burke, BI Diamondstone, RA Velapoldi, O Menis, Mechanisms of the Liebermann-Burchard and Zak color reactions for cholesterol, Clinical chemistry, 20, 7, (1974) 794-801

[4] M Suzery, Nurhasnawati E Ngadiwiyono, B Cahyono, Senyawa stigmasterol dari Pimpinella alpina Molk, Media Medika Indonesiana, Suppl, 29, 1, (2004) 37-39

[5] Robert Milton Silverstein, G. Clayton Bassler, Terence C. Morrill, Spectrometric Identification of Organic Compounds, 4 ed., Wiley, 1981.
[6] Suvi Kemmo, HPLC analysis of plant sterol oxidation products, (2008)

[7] MJ Moshi, E Innocent, JJ Magadula, DF Otieno, A Weisheit, PK Mbabazi, RSO Nondo, Brine shrimp toxicity of some plants used as traditional medicines in Kagera region, north western Tanzania, Tanzania journal of health research, 12, 1, (2010) 63-67 http://dx.doi.org/10.4314/thrb.v12i1.56287 